\title{
Biochemical, histopathological and ultra structural profile after pulsed water medication of enrofloxacin in broiler chickens
}

\author{
Veerapandian Sureshkumar, Ghadevaru Sarathchandra and Jayaramachandran Ramesh \\ Pharmacovigilance Laboratory for Animal Feed and Food Safety, \\ Directorate of Centre for Animal Health Studies, Tamil Nadu Veterinary and Animal Sciences University, \\ Madhavaram Milk Colony, Chennai - 600 051, Tamil Nadu, India \\ Corresponding author: Ghadevaru Sarathchandra, email: gsarathchandra@rediffmail.com \\ Received: 11-04-2013, Revised: 03-05-2013, Accepted: 04-05-2013, Published online: 12-07-2013
}

\begin{abstract}
How to cite this article:
Sureshkumar V, Sarathchandra G and Ramesh J (2013) Biochemical, histopathological and ultra structural profile after pulsed water medication of enrofloxacin in broiler chickens, Vet World 6(9): 668-673, doi: 10.14202/vetworld.2013.668-673
\end{abstract}

\begin{abstract}
Aim: A pharmacological study was undertaken to evaluate the safety and adverse effects of enrofloxacin administration in broiler chickens by assessing the serum biochemical parameters, associated histopathological and ultra structural changes in liver and kidney.

Materials and Methods: Birds in the treatment group were administered with enrofloxacin at the recommended therapeutic dose $10 \mathrm{mg} / \mathrm{kg}$ body weight via drinking water for five successive days, while the control group (untreated group) received non medicated water. Serum biochemical parameters viz., total protein, albumin, lactate dehydrogenase, alkaline phosphatase, creatine kinase, lipase, triglyceride, gamma glutamyl transferase, urea, uric acid and creatinine were estimated at 24hour and 48hour intervals during the dosing and withdrawal periods, respectively. Liver and kidney tissue samples collected from 1, 3 , 5,7 , and 9 days post treatment groups were subjected to histopathological and ultrastructural examinations.
\end{abstract}

Results: There was no significant change $(\mathrm{p}>0.05)$ in total protein, albumin, lactate dehydrogenase, alkaline phosphatase, creatine kinase, lipase, triglyceride and urea levels in the enrofloxacin administered broiler chickens at all the time points evaluated. However, a significant increase $(\mathrm{p}<0.05)$ in gamma glutamyl transferase, uric acid and creatinine levels were observed after the $4^{\text {th }}$ dose of the enrofloxacin and on day 1 post treatment. During the withdrawal period, the elevated levels declined gradually and showed the trend towards control values as evidenced by a statistically insignificant difference on 3,5 , 7 and 9 days post treatment when compared to that of control group. These biochemical changes were substantiated by histopathological and ultrastructural changes elicited in liver and kidney.

Conclusion: The reversible trend observed in serum biochemical parameters, histopathological and ultra structural alterations in liver and kidney during the withdrawal period suggests that enrofloxacin is safe if administered to broiler chickens at the recommended therapeutic dose and if the stipulated withdrawal period is strictly adhered to.

Keywords: biochemical parameters, broiler chickens, enrofloxacin, histopathology, ultrastructural, veterinary pharmacovigilance

\section{I ntroduction}

In the modern intensive poultry production, antimicrobial agents are being increasingly used to enhance feed efficiency, promote health, improve productivity, and are also used for disease prophylaxis and treatment $[1,2]$. In this context, it is important to note that the fluoroquinolones are synthetic antimicrobial agents used extensively in the poultry industry for the control of premature mortality and for the prophylaxis and treatment of respiratory, renal, and digestive infections [3,4]. Enrofloxacin is a fluoroquinolone that was developed exclusively for veterinary use and is currently used in large-scale in poultry, especially for the treatment of chronic respiratory disease, colibacillosis, salmonellosis and fowl cholera $[5,6]$. In vivo, enrofloxacin is metabolised into pharmacologically active metabolite ciprofloxacin by liver microsomal enzymes that belong to the cytochrome P450 family $[4,7]$.

This article is an open access article licensed under the terms of the Creative Commons Attribution License (http://creativecommons. org/licenses/by/2.0) which permits unrestricted use, distribution and reproduction in any medium, provided the work is properly cited.
The fluoroquinolones are considered relatively safe and well tolerated as indicated by earlier reports which demonstrated that enrofloxacin is well tolerated at the recommended dosage in cats $[8,9,10]$. However, it has been reported that fluoroquinolones are also associated with a low incidence of adverse effects related to gastrointestinal, skin, hepatic, central nervous system functions, and phototoxicity [11]. Further, there is evidence to show that enrofloxacin administration in broiler chickens resulted in a significant decline in the lymphocyte count [12] and reduction in haemagglutination inhibition (HI) titre and associated histopathological changes in the lymphoid organs [13].

Data on the safety regarding repeated oral administration of fluoroquinolones in poultry are very scarce [14]. Information on the residual effects of enrofloxacin and post market surveillance on serum biochemical parameters, histopathological and ultra structural changes in broiler chickens during the post treatment periods is lacking.

Hence, we conducted a pharmacological study in broiler chickens to assess the safety and adverse effects of enrofloxacin administration on serum biochemical 
Table-1. Effect of enrofloxacin administration $(10 \mathrm{mg} / \mathrm{kg}$ body weight, in drinking water for 5 successive days) on total protein, albumin, lactate dehydrogenase, alkaline phosphatase, creatine kinase, lipase and triglyceride levels (data is shown as Mean $\pm S E, n=6$ )

\begin{tabular}{|c|c|c|c|c|c|c|c|}
\hline & $\mathrm{TP}(\mathrm{g} / \mathrm{dL})$ & Albumin (g/dL) & LD (U/L) & $A P(U / L)$ & CK (U/L) & Lipase (U/L) & TG $(\mathrm{mg} / \mathrm{dL})$ \\
\hline Control & $2.88 \pm 0.13$ & $1.59 \pm 0.06$ & $1826.18 \pm 143.19$ & $1351.30 \pm 86.91$ & $1014.50 \pm 71.27$ & $21.34 \pm 1.31$ & $87.42 \pm 5.90$ \\
\hline After 1st dose & $3.01 \pm 0.04$ & $1.50 \pm 0.01$ & $1852.50 \pm 131.90$ & $1249.35 \pm 44.61$ & $1026.50 \pm 32.72$ & $20.36 \pm 1.13$ & $91.25 \pm 5.53$ \\
\hline 2nd dose & $3.14 \pm 0.07$ & $1.59 \pm 0.05$ & $1933.18 \pm 159.53$ & $1414.07 \pm 71.22$ & $1027.83 \pm 35.24$ & $23.67 \pm 1.79$ & $95.60 \pm 4.98$ \\
\hline 3rd dose & $3.03 \pm 0.06$ & $1.66 \pm 0.04$ & $1869.08 \pm 101.64$ & $1510.78 \pm 57.48$ & $1041.50 \pm 35.17$ & $25.27 \pm 2.51$ & $92.22 \pm 6.75$ \\
\hline 4th dose & $2.94 \pm 0.14$ & $1.51 \pm 0.08$ & $2014.80 \pm 095.23$ & $1358.47 \pm 86.64$ & $1107.00 \pm 54.64$ & $22.99 \pm 2.33$ & $98.35 \pm 6.36$ \\
\hline \multicolumn{8}{|c|}{ Post treatment } \\
\hline Day 1 & $3.20 \pm 0.23$ & $1.70 \pm 0.10$ & $1918.37 \pm 192.28$ & $1379.10 \pm 64.96$ & $1118.33 \pm 27.09$ & $26.67 \pm 1.36$ & $106.63 \pm 8.38$ \\
\hline Day 3 & $2.99 \pm 0.07$ & $1.65 \pm 0.06$ & $1985.72 \pm 103.05$ & $1424.35 \pm 84.83$ & $1060.50 \pm 33.56$ & $24.79 \pm 1.60$ & $106.10 \pm 4.75$ \\
\hline Day 5 & $3.13 \pm 0.07$ & $1.64 \pm 0.04$ & $1966.23 \pm 166.54$ & $1503.07 \pm 53.04$ & $1000.33 \pm 55.94$ & $25.62 \pm 1.84$ & $101.23 \pm 3.13$ \\
\hline Day 7 & $2.95 \pm 0.21$ & $1.51 \pm 0.07$ & $1871.40 \pm 160.28$ & $1439.40 \pm 86.04$ & $1021.00 \pm 51.46$ & $25.66 \pm 2.06$ & $97.97 \pm 8.39$ \\
\hline Day 9 & $2.82 \pm 0.04$ & $1.55 \pm 0.04$ & $1830.00 \pm 131.12$ & $1456.43 \pm 70.82$ & $1010.17 \pm 24.39$ & $20.34 \pm 1.30$ & $95.60 \pm 1.42$ \\
\hline
\end{tabular}

TP: Total protein, LD: Lacto dehydrogenase, AP: Alkaline phosphatase, CK: Creatinine kinase, TG: Triglyceride

Table-2. Effect of enrofloxacin administration $(10 \mathrm{mg} / \mathrm{kg}$ body weight, in drinking water for 5 successive days) on gamma glutamyl transferase, urea, uric acid and creatinine levels (data is shown as Mean $\pm S E, n=6$ )

\begin{tabular}{|c|c|c|c|c|}
\hline & Gamma glutamyl transferase(U/L) & Urea $(\mathrm{mg} / \mathrm{dL})$ & Uric acid (mg/dL) & Creatinine $(\mathrm{mg} / \mathrm{dL})$ \\
\hline Control & $21.53^{\mathrm{c}} \pm 2.28$ & $3.38 \pm 0.31$ & $4.86^{\mathrm{c}} \pm 0.57$ & $0.42^{c} \pm 0.01$ \\
\hline After 1st dose & $20.90^{c} \pm 0.49$ & $3.25 \pm 0.18$ & $5.26^{\mathrm{c}} \pm 0.38$ & $0.41^{\mathrm{c}} \pm 0.01$ \\
\hline 2nd dose & $25.20^{\mathrm{abc}} \pm 0.89$ & $3.40 \pm 0.36$ & $5.66^{\mathrm{bc}} \pm 0.00$ & $0.43^{\mathrm{bc}} \pm 0.02$ \\
\hline 3rd dose & $26.35^{\mathrm{abc}} \pm 5.67$ & $4.02 \pm 0.36$ & $6.10^{\mathrm{abc}} \pm 0.21$ & $0.42^{c} \pm 0.02$ \\
\hline 4th dose & $33.31^{\mathrm{a}} \pm 4.82$ & $3.97 \pm 0.19$ & $6.78^{\mathrm{ab}} \pm 0.16$ & $0.48^{\mathrm{ab}} \pm 0.03$ \\
\hline \multicolumn{5}{|l|}{ Post treatment } \\
\hline Day 1 & $32.47^{\mathrm{ab}} \pm 0.71$ & $4.13 \pm 0.29$ & $7.27^{\mathrm{a}} \pm 1.06$ & $0.52^{\mathrm{a}} \pm 0.03$ \\
\hline Day 3 & $28.85^{\mathrm{abc}} \pm 1.69$ & $3.90 \pm 0.34$ & $5.89^{\mathrm{abc}} \pm 0.74$ & $0.46^{\mathrm{bc}} \pm 0.01$ \\
\hline Day 5 & $25.83^{\mathrm{abc}} \pm 0.99$ & $4.03 \pm 0.19$ & $5.11^{\mathrm{c}} \pm 0.36$ & $0.45^{\mathrm{bc}} \pm 0.02$ \\
\hline Day 7 & $23.40^{\mathrm{C}} \pm 1.12$ & $3.30 \pm 0.09$ & $5.53^{\mathrm{bc}} \pm 0.21$ & $0.44^{\mathrm{bc}} \pm 0.03$ \\
\hline Day 9 & $23.93^{\mathrm{c}} \pm 4.08$ & $3.43 \pm 0.12$ & $5.50^{b c} \pm 0.36$ & $0.45^{\mathrm{bc}} \pm 0.03$ \\
\hline
\end{tabular}

Means bearing different superscripts $(a, b, c)$ within the column differ significantly $(p<0.05)$

parameters, and to thoroughly evaluate the associated histopathological and ultrastructural alterations in liver and kidney.

\section{Materials and Methods}

Ethical approval: Institutional Animal Ethics Committee (IAEC), Madras Veterinary College, TANUVAS has accorded permission for conducting this biological trial.

Medication with enrofloxacin containing water: 36 day old broiler chicks (Broiler strain $B_{1}$ ) acquired from Institute of Poultry Production and Management (IPPM), TANUVAS, Chennai-51 were randomly divided into control and treatment groups and were maintained under standard management conditions. Control group (I) received non medicated water while the treatment groups (II, III, IV, V and VI) were administered with enrofloxacin at recommended therapeutic dose of $10 \mathrm{mg} / \mathrm{kg}$ body weight, via drinking water for five successive days from 43rd to 47th day of age $[13,15]$. The pulsed water medication was given as per the methods described by Charleston et al. [16]. Birds received their freshly-prepared daily medication during a 4 hour period in the morning, and their water was antibiotic free for the remaining 20 hours in each day. The concentration of enrofloxacin in the water, to administer the required dose per $\mathrm{kg}$ of body weight, was calculated by determining the water consumption and body weight of each bird on the day of medication.

Serum biochemical parameters: Blood samples were collected from the wing vein at 24 hour interval during the dosing period and at 48 hour interval during the withdrawal period up to 9 days post treatment. Serum samples thus obtained were subjected to total protein, albumin, lactate dehydrogenase (LDH), alkaline phosphatase (ALP), creatine kinase (CK), lipase, triglyceride, gamma glutamyl transferase (GGT), urea, uric acid and creatinine estimation by auto analyzer (A-15, Bio-Systems) using standard kits. Statistical analysis was carried out by following One way analysis of variance as described by Snedecor and Cochran [17].

Histopathology: Treatment groups were sacrificed ethically on 1, 3, 5, 7 and 9 days post treatment and control birds were sacrificed on day 9 post treatment. Liver and kidney tissue samples were collected in 10\% formalin and were subjected to histopathological examination [18].

Ultrastructural study: Liver and kidney tissue samples from control and treatment groups (day 1 and day 9 post treatments) were collected immediately after sacrificing the birds and processed. Tissue sections were examined under a transmission electron microscope (Philips 2010, Netherlands) operated at 60KVA and photographed [18].

\section{Results}

Serum biochemical parameters: It is discernible from our results that there was no significant change ( $>0.05)$ in total protein, albumin, LDH, ALP, CK, lipase, triglyceride and urea levels in enrofloxacin 


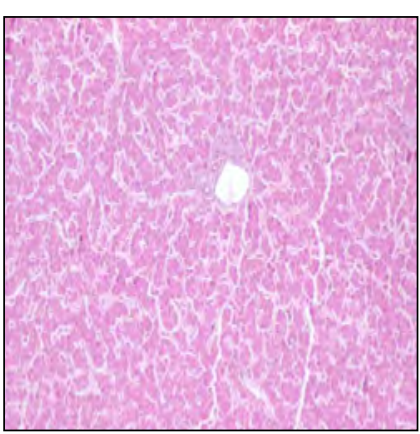

Figure-1. Liver of control group showing normal architecture. $H \& E, x 10$.

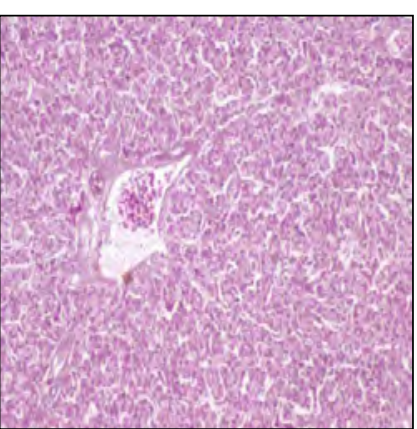

Figure-2. Liver of 1 day post ration of hepatocytes and areas of congestion. $H \& E, x 10$

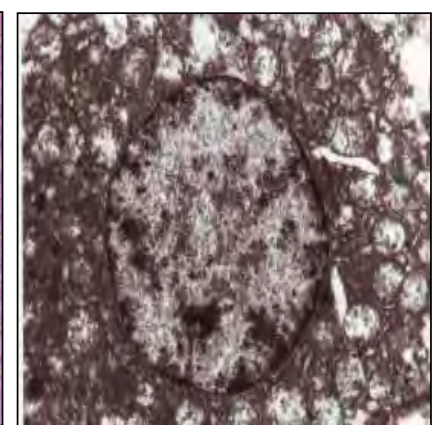

Figure-5. Liver of $9^{\text {th }}$ day post Figure-6. Liver of control group, treatment group showing mild normal hepatocytes with nucleus vacuolation of hepatocytes. and mitochondria. Uranyl acetate
$\mathrm{H} \& \mathrm{E}, \mathrm{x} 10$.

administered broiler chickens at all the time points evaluated (Table-1). However, a significant increase $(p<0.05)$ in GGT, uric acid and creatinine levels were observed after the $4^{\text {th }}$ dose of the enrofloxacin and on day 1 post treatment. The elevated levels declined gradually during the withdrawal period as evidenced by a statistically insignificant change starting from day 3 post treatment (Table-2).

\section{Histopathology and ultra structural study}

Histopathology of the liver: Liver of control group revealed no histological aberrations (Fig-1). On the other hand, on day 1 post treatment, hepatocytes were swollen and showed vacuolated cytoplasm. Degeneration of hepatocytes and areas of congestion were also observed (Fig-2). Whereas, on day 3 post treatment no sinusoidal space could be observed indicating that hepatocytes were highly swollen and also exhibited few areas of vacuolar degeneration with vacuolated cytoplasm (Fig-3). However, on day 5 post treatment sinusoidal spaces reemerged and samples from only a few birds showed focal areas of infiltrated inflammatory cells (Fig-4). Mild vacuolation of hepatocytes was the only appreciable lesion noticed on day 9 post treatment (Fig-5).

UItrastructural changes in the liver: Control group showed normal hepatocyte morphology pertaining to organelles such as nucleus, mitochondria and endoplasmic reticulum (Fig-6). In the treatment group,
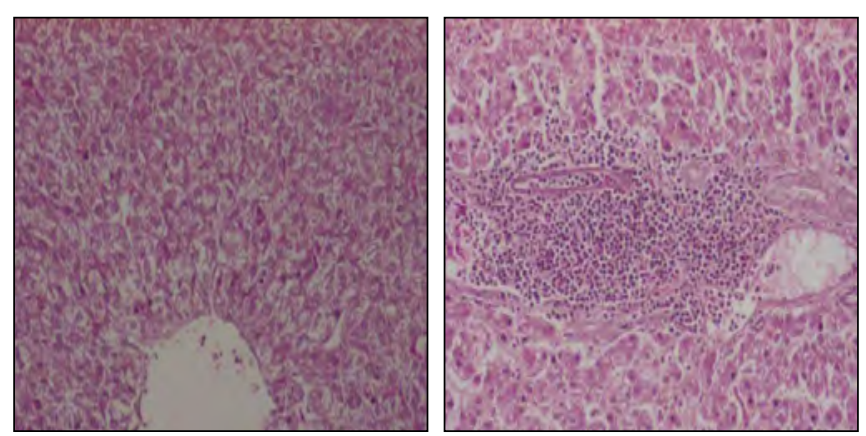

Figure-3. Liver of $3^{\text {rd }}$ day post Figure-4. Liver of $5^{\text {th }}$ day post treatment group showing no treatment chicken showing focal sinusoidal spaces indicating areas of infiltrated inflammatory swollen hepatocytes and few cells. $H \& E, x 20$. areas of vacuolar degeneration. $\mathrm{H} \& \mathrm{E}, \mathrm{x} 20$.
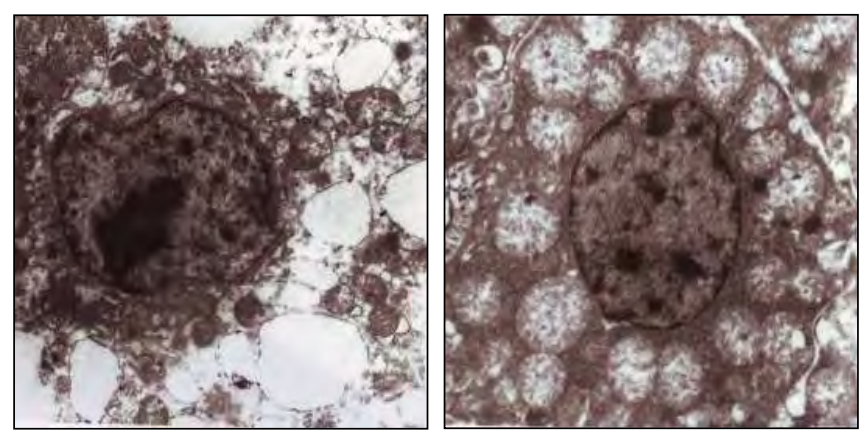

Figure-7. Liver of day 1 post Figure-8. Liver of $9^{\text {th }}$ day post treatment group showing hepato- treatment group with hepatocytes cytes with atrophied nucleus, showing mitochondrial swelling. vacuolated cytoplasm and swollen Uranyl acetate \& Reynold's mitochondria. Uranyl acetate \& solution, $\times 10000$.

Reynold's solution, x10000.

on day 1 post treatment, hepatocytes showed atrophied nucleus, cytoplasm was vacuolated with scattered cytoplasmic organelles and swollen mitochondria (Fig-7). While, in 9 day post treatment group hepatocytes showed normal nucleus but few cells had shrunken nucleus. Mitochondrial swelling was the only appreciable lesion observed in few cases (Fig-8).

Histopathology of the kidney: Control group showed normal features of kidney (Fig-9). Kidney from day 1 post treatment group revealed degeneration and necrosis of tubular epithelial cells with granular eosinophilic cytoplasm (Fig-10). On day 3 post treatment, degeneration of tubular epithelial cells with haemorrhagic areas were noticed. However, in few cases, cytoplasm of swollen tubular epithelial cells was filled with eosinophilic material (Fig-11). Degeneration of tubular epithelium persisted in day 5 post treatment group; however it was only mild and was also observed in only few cases (Fig-12). Indeed, mild swollen tubular epithelial cells were the only appreciable lesions observed on day 7 and 9 post treatment (Fig13).

Ultrastructural changes in the kidney: Control group revealed normal glomeruli and tubular epithelial cells with unaltered brush border (Fig-14). In 1 day post treatment group, normal architecture of glomeruli and tubular epithelial cells vanished. Prominent features of the tubular epithelium include shrunken nucleus, 

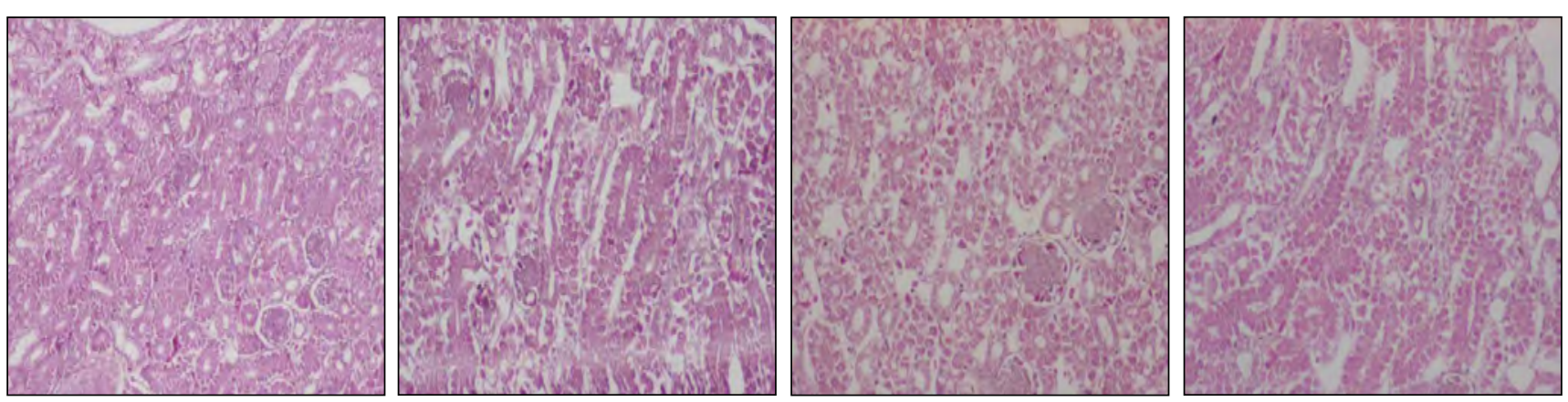

Figure-9. Kidney of control group Figure-10. Kidney of 1 day post Figure-11. Kidney of $3^{\text {rd }}$ day post Figure-12. Kidney of $5^{\text {th }}$ day post showing normal glomeruli and treatment group showing treatment group showing treatment chicken showing mild tubular epithelial cells. $\mathrm{H} \& \mathrm{E}, \mathrm{x} 10$. degeneration and necrosis of degeneration of tubular epithelial tubular degeneration. H\&E, $\times 20$. tubular epithelial cells with cells with haemorrhagic areas. granular eosinophilic cytoplasm. H\&E, x20. $\mathrm{H} \& \mathrm{E}, \mathrm{x} 20$.
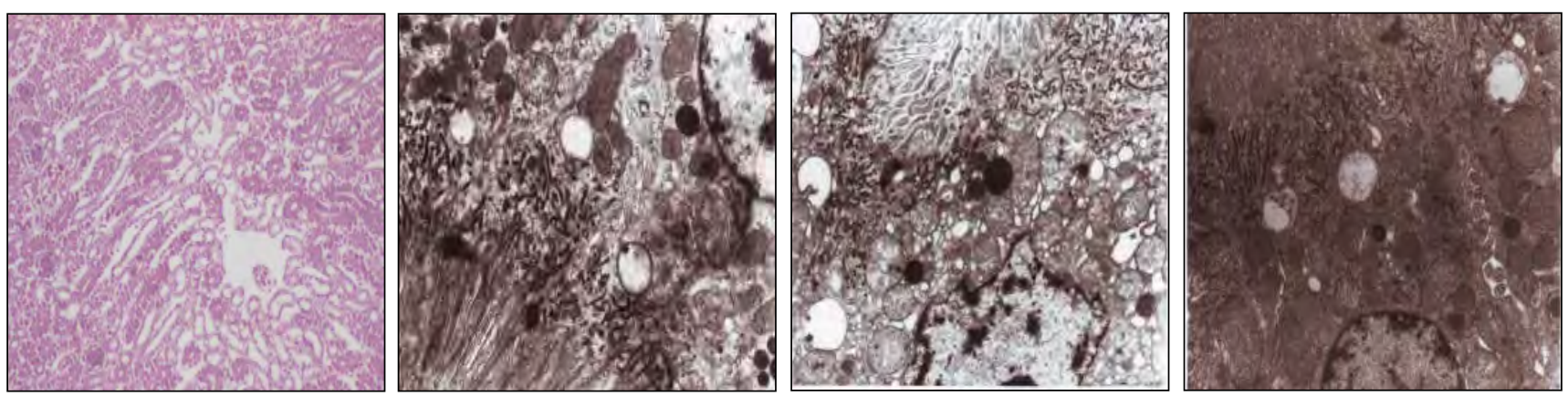

Figure-13. Kidney of $9^{\text {th }}$ day post Figure-14. Kidney of control Figure-15. Kidney of day 1 post Figure-.16. Kidney of $9^{\text {th }}$ day post treatment group showing mild group showing normal tubular treatment group showing tubular treatment group showing tubular tubular degenerative changes. epithelial cells with unaltered epithelium with shrunken nucleus, epithelial cells with normal $H \& E, x 10$.

brush border. Uranyl acetate \& Reynold's solution, $\mathrm{x} 10000$

swollen mitochondria, vacuolated cytoplasm and attrition of brush border (Fig-15). However, mild vacuolation in cytoplasm and swollen mitochondria were the only considerable lesions found in the 9 day post treatment group (Fig-16).

\section{Discussion}

In the present study, the serum biochemical parameters revealed insignificant changes in total protein, albumin, LDH, ALP, CK, lipase, triglyceride and urea levels in enrofloxacin administered broiler chickens at all the time points evaluated. This finding is in accordance with Elkholy et al. [19], who showed that administration of Enrotryl ${ }^{\circledR}$ and Baytril ${ }^{\circledR}$ at a dose equivalent to $10 \mathrm{mg}$ enrofloxacin base $/ \mathrm{kg}$ body weight daily for five successive days, to laying hens induced insignificant changes in serum glucose, cholesterol, creatinine levels, serum alanine amino transferase (ALT), aspartate amino transferase (AST) and ALP activities.

However, Moustafa et al. [20] reported that administration of enrofloxacin in high doses (100, 200 and $400 \mathrm{ppm}$ through drinking water) for long periods (6 weeks) was accompanied with adverse effects on different organs along with elevated levels of AST, ALT, ALP, urea, uric acid and creatinine, hypoproteinaemia and hypoalbuminaemia. In addition, Tras et al. [21] showed that enrofloxacin injection at the

\begin{abstract}
balonised mitochondria, vacuolated nucleus, brush border, but with cytoplasm and attrition of brush mild mitochondrial swelling. border. Uranyl acetate \& Reynold's Uranyl acetate \& Reynold's solution, $\times 10000$. solution, $\mathrm{x} 10000$.
\end{abstract}

recommended dose of $5 \mathrm{mg} / \mathrm{kg} \mathrm{IM}$, once daily to healthy dogs for 14 days, caused transient increases in AST and mean corpuscular volume levels. Similar effects are reported in humans receiving ciprofloxacin and norfloxacin $[22,23]$.

Serum GGT is a highly specific and indicative enzyme for liver function and more sensitive than transaminases (AST and ALT) and ALP. A significant elevation in serum GGT level was observed after the 4th dose of enrofloxacin administration and on day 1 post treatment GGT levels showed a tendency to decline gradually during the withdrawal period. These findings were supported by Ellakany et al. [24] who also reported a similar trend that enrofloxacin at $100 \mathrm{mg} / \mathrm{kg}$ body weight in broiler chicken for 5 consecutive days caused elevation of serum ALT, but 6 days after the withdrawal the values returned to the control levels. Similarly, the authors further reported that serum AST level was found to be higher than the control group, albeit not significant, in those receiving $100 \mathrm{mg} / \mathrm{kg}$ body weight or $10 \mathrm{mg} / \mathrm{kg}$ body weight enrofloxacin, then decreased after withdrawal of the drug.

In the present study, the elevated levels of GGT can be correlated with the histopathological changes in the liver observed during the withdrawal period. For example, on day 1 post treatment hepatocytes were swollen, degenerated with vacuolated cytoplasm and 
showed areas of congestion. Vacuolar degeneration was persistent till $3^{\text {rd }}$ day post treatment, however, during the subsequent withdrawal period the lesions were mild as indicated by clear sinusoidal spaces and focal areas of infiltrated inflammatory cells with only a mild vacuolation of hepatocytes. These observations are in conformity with Ellakany et al. [24]. Further, Shawky et al. [25] also showed that enrofloxacin administered at $400 \mathrm{ppm}$ for 6 weeks produced histopathological changes in liver. Vaccaro et al. [26] opined that the major cause of enrofloxacin-induced hepato toxicity can be attributed to the inhibition of hepatic cytochrome P450 enzymes which are responsible for drug metabolism.

Hepatocellular injury represented by significant elevations in the serum GGT activities was further ascertained by the electron microscopic examination of liver samples of broiler chickens administered with enrofloxacin. Shrunken nucleus, swollen mitochondria and vacuolated cytoplasm with scattered cytoplasmic organelles are clearly indicative of hepatocyte degeneration and these changes were observed on day 1 post treatment group. However, in day 9 post treatment group mitochondrial swelling is the only appreciable lesion found in few cases. Similar observations using electron microscopy were made by El Daly [27] in the livers of rats that were administered with $10 \%$ enrofloxacin with a daily dose of $75 \mathrm{mg} / \mathrm{kg}$ body weight for 10 days intraperitoneally. The authors demonstrated that enrofloxacin induces the production of free radicals that cause oxidative stress to hepatocytes and its organelles, particularly to mitochondria and cell membranes.

A significant but transient elevation in serum uric acid and creatinine was noticed after the $4^{\text {th }}$ dose and on day 1 post treatment of enrofloxacin and evinced similar trend as that of GST during the withdrawal period. These biochemical changes were in harmony with histopathological alterations in kidneys which showed degeneration and necrosis of tubular epithelial cells with granular eosinophilic cytoplasm in day 1 post treatment group. However, a reversible tendency was noticed as evidenced by mild swollen tubular epithelial cells which were the only appreciable lesions observed on day 7 and 9 post treatment. Ellakany et al. [24] also found congestion, tubular degeneration, and areas of hemorrhage in kidney of broiler chicken administered with enrofloxacin at $100 \mathrm{mg} / \mathrm{kg}$ body weight through drinking water for 5 consecutive days.

Kidney injury as evidenced by significant elevation in the serum uric acid and creatinine levels was further bolstered by results from the electron microscopic examination of kidneys isolated from enrofloxacin administered broiler chickens. Indeed, mild vacuolation and mitochondrial swelling were the only considerable lesions found in the day 9 post treatment group suggestive of a reversible trend in the lesions during the withdrawal period.

\section{Conclusion}

Enrofloxacin administration at recommended therapeutic dose caused insignificant changes in total protein, albumin, LDH, ALP, CK, lipase, triglycerides and urea levels. A significant but transient elevation in GGT, uric acid and creatinine was noticed and these biochemical alterations were suggestive of histopathological and ultrastructural changes observed in liver and kidney. The restoration towards the control values of biochemical parameters accompanied by reversal of histopathological and ultra structural lesions towards normal contour during the withdrawal period clearly suggests that enrofloxacin is extremely safe if administered at recommended therapeutic dose and if the stipulated withdrawal period is strictly followed. Adhering to these precautions can prevents any adverse drug reactions and untoward residual effects.

\section{Authors' contributions}

This study is a significant component of the work towards the Ph.D. thesis of the first author VS, submitted to Tamil Nadu Veterinary and Animal Sciences University, Chennai-51. GS was the Chairman and designed the trial. VS conducted the experimental trial. JR performed the sampling. GS and VS analysed and interpreted the data, organised and thoroughly revised the manuscript. All authors read and approved the final version of the manuscript.

\section{Acknowledgements}

The Authors are highly grateful to Drugs and Pharmaceutical Research Programme, Department of Science and Technology (DST), Government of India, New Delhi, for the financial support as part of the DST scheme entitled "A National Facility for Pharmacovigilance on Drug Residue and other Toxic Xenobiotics including Genetically Manipulated Organisms in Veterinary Products" at Pharmacovigilance Laboratory for Animal Feed and Food Safety, DCAHS, TANUVAS, Chennai-600 051. The authors express profound thanks to Dr. S. Vairamuthu, Ph.D., Associate Professor and Head, Centralised Clinical Laboratory, Madras Veterinary College, Chennai for providing Auto analyser facility for the biochemical estimation of various parameters. The authors also thank Mrs. Rita Rajan, Technician, Wellcome Research Laboratory, Department of Gastrointestinal Sciences, Christian Medical College, Vellore, for help with Transmission Electron Microscopy.

\section{Competing interests}

The authors declare that they have no competing interests.

\section{References}

1. Johnston, A.M. (1998) Use of antimicrobial drugs in veterinarypractice. Br. Med.J. 317: 665-667.

2. Prescott, J.F., Baggot, J.D. and Walker, R.D. (2000) Fluoroquinolones, In: Prescott, J.F.,Baggot, J.D. and Walker, R.D., editors, Antimicrobial Therapy in Veterinary Medicine, $3^{\text {rd }}$ edition. Ames: Iowa State University Press. 
315-339.

3. Martinez, M., McDermontt, P. and Walker, R. (2006) Pharmacology of the fluoroquinolones: a perspective for the use in domestic animals. Vet. J. 172: 10-28.

4. Papich, M.G. and Riviere, J.E. (2009) Fluoroquinolone antibacterialdrugs. In: Riviere, J.E. and Papich, M.G., editors, Veterinary Pharmacology and Therapeutics. $9^{\text {th }}$ edition. Wiley-Blackwell, Iowa State University Press, USA. 983-1011.

5. Anderson, A.D., Nelson, J.M., Rossiter, S. and Angulo, F.J. (2003) Public health consequences of use of antimicrobial agents in food animals in the United States. Microb Drug Resist. 9: 373-379.

6. Wagman, A.S. and Wentland, M.P. (2007) Quinolone antibacterial agents. Comprehensive Medicinal Chemistry II, Chapter 7, 567-596.

7. Taccetti, G., Campana, S., Neri, A., Boni, V. and Festini, F. (2008) Antibiotic therapy against Pseudomonas aeruginosa in cystic fibrosis. J. Chemother. 20: 166-169.

8. Kordick, D., Papich, M. and Breitschwerdt, E. (1997) Efficacy of enrofloxacin or doxycycline for treatment of Bartonella henselae or Bartonella clarridgeiae infection in cats. Antimicrob Agents Chemother. 41:2448-2455.

9. Todorov, T. (2004) A preclinical study on Biofloxavet C (enrofloxacin) tolerance in cats. Bulg J Vet Med. 7: 239-244.

10. Shoorijeh, S.J., Tamadon, A., Vahedi, M. and Behzadi, M.A. (2012) Hematological and biochemical alterations due to over dosage of enrofloxacin in cats. Pak Vet J. 32: 73-76.

11. Hooper, D.C. and Wolfson, J.S. (1985) The fluoroquinolones: pharmacology, clinical uses, and toxicities in human. Antimicrob. Agents Chemother. 28: 716-721.

12. Sureshkumar, V., Sarathchandra, G., Ramesh, J., Vairamuthu, S., Thejomoorthy, P. and Hariharan, P. (2012) The effect of enrofloxacin administration on haematological profile in broiler chicken - A safety pharmacology study. The Indian Journal of Field Veterinarians. 8: 20-24.

13. Sureshkumar, V., Saratchandra, G. and Ramesh, J. (2013) Effect of enrofloxacin on Zootechnical performance, behaviour and immunohistopathological response in broiler chicken. Veterinary World. 6:337-342, doi: 10.5455/ vetworld. 2013.337-342.

14. Patel, J.H., Varia, R.D., Patel, U.D. and Vihol, P.D. (2009) Safety level of levofloxacin following repeated oral administration in White Leghorn layer birds. Vet. World. 2: 137-139.

15. Knoll, U., Glunder, G. and Kietzmann, M. (1999)
Comparative study of the plasma pharmacokinetics and tissue concentrations of danofloxacin and enrofloxacin in broiler chickens. J. Vet. Pharmacol. Therap., 22: 239-246.

16. Charleston, B., Gate, J.J., Aitken, I.A., Stephan, B. and Froyman, R. (1998) Comparison of the efficacies of three fluoroquinolone antimicrobial agents, given as continuous or pulsed-water medication, against Escherichia coli infection in chickens. Antimicrob.Agents Chemother. 42:83-87.

17. Snedecor, G.W. and Cochran, W.G. (1994) Statistical methods, $8^{\text {th }}$ Edn., Ames: Iowa State University Press.

18. Bancroft, J.D. and Gamble. M. (2008) Theory and practice of histological techniques. $6^{\text {th }}$ edition. Churchill Livingstone, Philadelphia.

19. Elkholy, H.M., Elkomy, A.A., Awidat, S.K. and Elmajdoub, A.A. (2009) Tissue and egg residues and adverse effect of two oral enrofloxacin preparations; Baytril ${ }^{\circledR}$ and Enrotryl ${ }^{\circledR}$. Global Veterinaria, 3:363-368.

20. Moustafa, A., Baset Abdel, I., El Mashad, A. and Tantawy, A. (1998) Pathological studies on enrofloxacin and its residues in broiler's chickens. Egypt. J. Comp. Pathol. Clin. Pathol. 11:57-66.

21. Tras, B., Maden, M., Bas, A.L., Elmas, M., Yazar, E. and Civelek, T. (2001) Investigation of biochemical and haematological side-effects of enrofloxacin in dogs. J. Vet MedA.48:59-63.

22. Davoren, P. and Mainstone, K. (1993) Norfloxacin-induced hepatitis. Med JAust.159: 423-424.

23. Jones, S.E. and Smith, R.H. (1997) Quinolones may induce hepatitis. BrMed J.314: 869-870.

24. Ellakany, H.F., Abu El-Azm, I.M., Bekhit, A.A. and Shehawy, M.M. (2007) Studies on the effects of enrofloxacin overdose on different health parameters in broiler chickens BS. Vet. Med. J. $5^{\text {th }}$ Scientific Conference, 176-186.

25. Shawky, M.A., Abdel-Baset, I., El-Mashad and Tantawy, A.A. (1998) Pathological studies on enrofloxacin and its residues in broiler chickens. Egypt. J. Comp. Pathol. Clin. Pathol. 11: 57-66.

26. Vaccaro, E., Giorgi, M., Longo, V., Mengozzi, G. and Cervasi, P.G. (2003) Inhibition of cytochrome P450 enzymes by enrofloxacin in the sea bass (Dicentrarchus labrax). Aquat. Toxicol.62: 27-33.

27. El Daly, A.A.A. (2011) The protective effect of green tea extract against enrofloxacin action on the rat liver; histological, histochemical and ultrastructural studies. J. Am. Sci. 7: 669679. 